NBER WORKING PAPER SERIES

HEPATITIS B DOES NOT EXPLAIN MALE-BIASED SEX RATIOS IN CHINA

Emily Oster

Gang Chen

Working Paper 13971

http://www.nber.org/papers/w13971

NATIONAL BUREAU OF ECONOMIC RESEARCH

1050 Massachusetts Avenue

Cambridge, MA 02138

May 2008

Larry Katz and Steve Levitt provided helpful feedback. I am grateful to the Haimen CDC for their work in running this study. The views expressed herein are those of the author(s) and do not necessarily reflect the views of the National Bureau of Economic Research.

NBER working papers are circulated for discussion and comment purposes. They have not been peerreviewed or been subject to the review by the NBER Board of Directors that accompanies official NBER publications.

(C) 2008 by Emily Oster and Gang Chen. All rights reserved. Short sections of text, not to exceed two paragraphs, may be quoted without explicit permission provided that full credit, including $\odot$ notice, is given to the source. 
Hepatitis B Does Not Explain Male-Biased Sex Ratios in China

Emily Oster and Gang Chen

NBER Working Paper No. 13971

April 2008

JEL No. J1,J16

\begin{abstract}
$\underline{\text { ABSTRACT }}$
Earlier work (Oster, 2005) has argued, based on existing medical literature and analysis of cross country data and vaccination programs, that parents who are carriers of hepatitis B have a higher offspring sex ratio (more boys) than non-carrier parents. Further, since a number of Asian countries, China in particular, have high hepatitis B carrier rates, Oster (2005) suggested that hepatitis B could explain a large share \{ approximately 50\% \{ of Asia's Imissing women". Subsequent work has questioned this conclusion. Most notably, Lin and Luoh (2008) use data from a large cohort of births in Taiwan and find only a very tiny effect of maternal hepatitis carrier status on offspring sex ratio. Although this work is quite conclusive for the case of mothers, it leaves open the possibility that paternal carrier status is driving higher sex offspring sex ratios. To test this, we collected data on the offspring gender for a cohort of 67,000 people in China who are being observed in a prospective cohort study of liver cancer; approximately $15 \%$ of these individuals are hepatitis B carriers. In this sample, we find no effect of either maternal or paternal hepatitis B carrier status on offspring sex. Carrier parents are no more likely to have male children than non-carrier parents. This finding leads us to conclude that hepatitis B cannot explain skewed sex ratios in China.
\end{abstract}

\author{
Emily Oster \\ University of Chicago \\ Department of Economics \\ 1126 East 59th Street \\ Chicago, IL 60637 \\ and NBER \\ eoster@uchicago.edu \\ Gang Chen \\ Hepatitis B Foundation \\ Philadelphia, PA \\ gang.chen@drexel.edu
}




\title{
Hepatitis B Does Not Explain Male-Biased Sex Ratios in China
}

\author{
Emily Oster* \\ Gang Chen \\ University of Chicago and NBER \\ Hepatitis B Foundation \\ Xinsen $\mathrm{Yu}$ \\ Haimen CDC \\ Wenyao Lin \\ Haimen CDC
}

Draft: April 16, 2008

\begin{abstract}
Earlier work (Oster, 2005) has argued, based on existing medical literature and analysis of cross country data and vaccination programs, that parents who are carriers of hepatitis B have a higher offspring sex ratio (more boys) than non-carrier parents. Further, since a number of Asian countries, China in particular, have high hepatitis B carrier rates, Oster(2005) suggested that hepatitis B could explain a large share - approximately 50\% - of Asia's "missing women". Subsequent work has questioned this conclusion. Most notably, Lin and Luoh (2008) use data from a large cohort of births in Taiwan and find only a very tiny effect of maternal hepatitis carrier status on offspring sex ratio. Although this work is quite conclusive for the case of mothers, it leaves open the possibility that paternal carrier status is driving higher sex offspring sex ratios. To test this, we collected data on the offspring gender for a cohort of 67,000 people in China who are being observed in a prospective cohort study of liver cancer; approximately $15 \%$ of these individuals are hepatitis B carriers. In this sample, we find no effect of either maternal or paternal hepatitis B carrier status on offspring sex. Carrier parents are no more likely to have male children than non-carrier parents. This finding leads us to conclude that hepatitis B cannot explain skewed sex ratios in China.
\end{abstract}

\section{Introduction}

Earlier work (Oster, 2005) has argued that a high rate of hepatitis B carrier status in China explains a large share of the male-biased gender ratio - the "missing women" phenomenon - in that country and, more generally, that high rates of hepatitis in a number of Asian countries explained some of the skewed gender ratios there. This conclusion was based first on evidence from an existing medical literature suggesting that families where at least one parent is a carrier of the hepatitis B virus had a larger share of male children (Hesser, Economidou and Blumberg, 1975; Drew, London, Blumberg and Serjeanston, 1982; Drew, Blumberg and Robert-Lamblin, 1986; Chahnazarian, Blumberg and London, 1988; Cazal, Lemiare and Robinet-Levy, 1976; Livadas et al, 1979). Oster (2005)

\footnotetext{
*Larry Katz, Steve Levitt and Andrei Shleifer provided helpful feedback. We are grateful to the Haimen CDC for their work in running this study.
} 
supplemented this existing evidence with evidence on vaccination campaigns, notably in Alaska, and cross country evidence suggesting that countries with higher hepatitis B carrier rates have higher male-to-female ratios. In summary, the evidence suggested that families with a hepatitis B carrier parent had children that were $60 \%$ male, versus $51 \%$ in the overall population.

Subsequent to that research, a number of papers have emerged questioning the conclusions in Oster (2005). Several papers have questioned the evidence on skewed sex ratios in China, arguing that these skewed ratios, at least in recent years, appear only at higher order births, which may be inconsistent with the hepatitis B hypothesis (Das Gupta, 2005; Ebenstein, 2007). Most notably, Lin and Luoh (2008) have used a new, individual-level, dataset to test the underlying premise that hepatitis B carrier status is related to sex ratio. In a sample of approximately 3 million births in Taiwan, they find that women who are carriers of hepatitis B are only very slightly more likely to have male children than non-carriers. The effect is approximately 0.25 percentage points.

The dataset used by Lin and Luoh (2008) is much larger than the original individual-level studies reported in the medical literature (most of these had only a few hundred or thousand children) and is consequently quite convincing on the relationship between maternal hepatitis status and offspring gender. However, Lin and Luoh (2008) only observe maternal status, whereas the original data, and the analysis in Oster (2005) focuses on infection at the family or population level. These data therefore leave open the possibility that paternal hepatitis B infection could be responsible for skewed gender ratios. Indeed, in a re-analysis of the original data from Greece and the Philippines (reported in detail in Chen, Oster, Yu and Lin (2008)) we see that paternal carrier status, not maternal, is associated with higher offspring sex ratios.

To test the effect of both maternal and paternal carrier status we have collected data on approximately 67,000 individuals in China, taking advantage of a cohort of individuals already taking part in a study of liver cancer and the effect of hepatitis B on health (this cohort is reported on in more detail in London et al, 1995 and Evans et al, 2002). From earlier surveys of this cohort, data was available on hepatitis B carrier status (approximately 15\% of individuals are carriers). Our survey, described in more detail in Section 2, collected data on the gender of offspring. Since the sample includes both men and women, and in some cases links spouses together, it is possible to estimate the effect of both maternal and paternal hepatitis B carrier status.

Using this data, we find no effect of either paternal or maternal hepatitis B carrier status on offspring sex ratio. Estimates of the effects on child gender are extremely close to zero, inconsistently signed and have small standard errors. This is true with and without controls for age, township and 
child birth order. This demonstrates that hepatitis B carrier status cannot explain male-biased sex ratios in China. The rest of this brief note reports in more detail on these findings. Section 2 describes the survey run in China, Section 3 presents our results on sex ratios and Section 4 concludes.

\section{Survey Description}

This study takes advantage of an existing cohort study of individuals in China who are being followed in order to evaluate the impact of chronic hepatitis B status on health, focusing on liver cancer. Detailed data on the enrollment and study of this cohort can be found elsewhere (Evans et al, 2002; London et al, 1995). This is a large, prospective cohort study of adult residents in rural areas around Haimen City in the Jiangsu Province. Subjects were originally recruited in 1992, and have been followed since then. At enrollment, individuals completed a one-page questionnaire with details on age, behaviors (smoking, alcohol consumption) and family history (particularly, history of liver cancer). Individuals also gave blood, which was tested for hepatitis B carrier status (and in some cases other hepatitis B markers). The original cohort contained 90,836 adult residents of this area. Although follow-up has been done periodically with these subjects, they have never been asked details about their offspring.

Data on child gender was collected by the Haimen CDC in the period between December, 2007 and February, 2008, for 67,511 of the original subjects. Re-surveying all of the individuals would have been prohibitively expensive (and difficult since approximately $10 \%$ of them had died). As an alternative, we asked officials in each village to report information on the children of cohort members who lived in their village. In each village, we invited the village head, party secretary of the village, the village doctor, the village accountant and any other village administrative staff to come together and provide data on cohort members' children. They were given a list of cohort participants in their village and asked to report the gender and status (alive, dead) for any children born to these individuals, by birth order. Observation of these meetings suggests that the administrators made use of official records of births and families, as well as personal recollection. In addition, an extremely large share of the (living) individuals in the cohort had telephones, and in cases where they were unsure, the administrators phoned the cohort member themselves.

In addition to this, we collected quality control data on 2,590 participants. This quality control focused on cohort members with 4 or more children, since pilot surveys suggested that this 
was the group for which administrators were most likely to make errors. In addition to the basic data on gender and status, the quality control data also asked details about abortions or miscarriages that the respondent was aware of. Comparing the quality control to the larger dataset, the surveyors found a $2.82 \%$ error rate in the first round of data provided by the administrators ${ }^{1}$ In situations where there were mis-matches (i.e. the quality control did not mach with the officially provided data) the data was sent back to the village administrators and they were asked to re-check everything. If necessary, this process was repeated more than once to ensure maximum overall data quality. In the results section below, we will report results both for the overall sample and for the quality control data alone. We will also report results for various sub-samples (younger people, those with fewer children, etc) for whom we think errors are even less likely.

Table 1 reports summary statistics for the overall sample, and the quality control. Sixty-four percent of the overall sample is male (representing a purposeful over sampling of the original survey, since men are more likely to be hepatitis B carriers) and $15.4 \%$ of them are carriers of hepatitis B. The average individual has 1.0 male children, and 0.95 female children, reflecting an overall slightly skewed sex ratio in the population. Individuals in the sample range in age from 34 to 84 , with an average of 58 . Among the sample, approximately $10 \%$ of respondents had died by the most recent survey $\left.\right|^{2}$ and $1.8 \%$ of the children of sample participants had died. Finally, for $13 \%$ of the sample we also have their spouse included in the cohort. This will allow us to estimate the effect of maternal and paternal carrier status at the same time, for some share of the sample.

The quality control sample is slightly more skewed towards men (73\%) and has a slightly smaller share of hepatitis carriers $(13 \%)$. The sample has more children, on average, due to the method of selection, and is older. The older age reflects the sample selection: because of the one-child rule, younger people typically do not have 4 or more children. Death rates among cohort members in this sample are zero, since only living people could be contacted, but the death rate among their offspring is higher, at 5.7\%. This also reflects the selection of larger families and older parents: among families of a similar size in the overall sample, death rates are similar.

\footnotetext{
${ }^{1}$ It is worth noting the error rate would likely be lower if we had not specifically focused on quality control for the group where they thought there was most likely to be mistakes.

${ }^{2}$ Because of the data collection technique, it was possible to get information on offspring even of people who had died. Of course, quality control was not possible with this sub-sample.
} 


\section{Results: Effect of Hepatitis B on Offspring Sex Ratio}

Figure 1 shows the primary results in the paper, focusing on the overall sample. The first set of columns focuses on paternal carrier status: among men who are carriers, $51.06 \%$ of their offspring are boys. Among non-carriers, this is $51.56 \%$. For mothers, the numbers are $51.58 \%$ and $51.43 \%$. The final set of columns compares children for whom both parents are carriers to children for whom neither parent is a carrier; the share of males among offspring are $49.45 \%$ and $50.68 \%$, respectively. This graph suggests there is no substantial difference in child gender by parental hepatitis B carrier status.

Table 2 reports regression results focusing on the overall sample. Panel A shows the relationship between gender and parental hepatitis carrier status with no controls (corresponding exactly to Figure 1). As expected based on Figure 1, neither paternal nor maternal carrier status significantly impacts child gender, and including them jointly shows a similar result. Panel B of Table 2 includes a simple set of controls: child birth order, number of children in the family, a quadratic in parent age and fixed effects for township (to capture location or income effects) ${ }^{3}$. Again, we see no effect of carrier status on gender. We do see some effects of birth order - consistent with other work on parity, later birth order children are more likely to be boys. We also see a negative effect of number of children - larger families have fewer boys. This is consistent with a gender-biased stopping rule, which may well be in play here.

One concern with these data, as discussed, is the possibility of errors based on the data collection process; in particular, the possibility that village leaders are unable to recall details related to residents' children. Although there is no reason to think this would be bias the results in any particular direction, we re-run the analysis with two sub-samples for whom we think this misreporting is less likely. First, in Panel A of Table 3 we limit the sample to individuals who are under 60 and who are alive, for whom we think recall by others is likely to be easier. We see no effect of hepatitis status on gender for this group. Second, in Panel B of Table 3 we limit to families with only one child, where the gender of the child is likely to be salient and there is no issue with mis-reporting gender by birth order. Again, we see no positive effect in this sub-sample; there appears to be some negative effect of maternal hepatitis carrier status on gender in the sample for which we observe both parents, but this is a very small sample, and this result does not seem to be generally robust.

\footnotetext{
${ }^{3}$ We have also experimented with controlling for other behavioral and health measures - alcohol or smoking abuse, exposure to pesticides, family history of liver cancer - and these do not change the result.
} 
Table 4 replicates the regressions above using the quality control sample. In this case, we focus on using all of the quality control data, since the sample size is limited to begin with. In addition, because of the limited sample size it is not possible to look at the effect of maternal and paternal infection at the same time. However, in the samples separated by gender, we see confirmation of the results in Tables 2 and 3: no effect of parent carrier status on child gender.

\section{Discussion and Conclusion}

Tables 2 through 4 and Figure 1 all point to a similar conclusion: in this sample we see no effect of parental hepatitis B carrier status on offspring gender. Given this result, we conclude that hepatitis B carrier rates cannot explain male-biased sex ratios or the "missing women" in China. The evidence is consistent with the finding in Lin and Luoh (2008), but also allows us to estimate the effect of paternal hepatitis carrier status.

An important remaining issue is whether it is possible to reconcile the biological results in the original paper (Oster, 2005) with these results and, in particular, how the individual-level data from outside of China and the evidence from vaccination campaigns in Alaska can coexist with the new results from China. In Chen, Oster, Yu and Lin (2008) we address this issue in more detail. We re-visit the original individual-level data from Greece and the Philippines and continue to find support for the connection between paternal hepatitis B carrier status and offspring sex ratio. Moreover, in the data from China discussed here, we also find some interaction between hepatitis B, gender and fertility: women with the hepatitis $\mathrm{B} e$ antigen (carriers who are also replicating an additional viral antigen) seem to have fewer male children. Further, women who are carriers of the virus have fewer children overall, even with extensive controls. Together, this evidence suggests that there may still be some interaction between hepatitis B and fertility outcomes (in general) but that clearly the pathways are much more complicated than the simple carrier-male offspring connection. One possibility is that the interaction differs with different genotypes of the hepatitis B virus, but that is not something we can prove definitively with the existing data. Further research would be required to settle this question. 


\section{References}

Cazal, P, JM Lemiare, and M Robinet-Levy, "Hepatitis B et Rapport du Masculinite," Revue franaise de transfusion et immunohmatologie, 1976, 19, 577-581.

Chahnazarian, Anouch, Baruch Blumberg, and W. Thomas London, "Hepatitis B and the Sex Ratio at Birth: a Comparative Analysis of Four Populations.," Journal of Biosocial Science, July 1988, 20 (3), 357-370.

Chen, Gang, Emily Oster, Xinsen Yu, and Wenyao Lin, "Hepatitis B and Sex Ratios at Birth: Re-visiting the Relationship," Mimeo, University of Chicago, 2008.

Das Gupta, Monica, "Explaining Asia's "Missing Women": A New Look at the Data," Population and Development Review, September 2005, 31 (3), 529-535.

Drew, Jean, Baruch Blumberg, and J Robert-Lamblin, "'Hepatitis B Virus and Sex Ratio of Offspring in East Greenland."," Human Biology, February 1986, 58 (1), 115-120.

_ , W. Thomas London, Baruch Blumberg, and Susan Serjeanston, "Hepatitis B Virus and Sex Ratio on Kar Kar Island."," Human Biology, February 1982, 54 (1), 123-135.

Ebenstein, Avraham, "Fertility Choices and Sex Selection in Asia: Analysis and Policy," Mimeo, University of California Berkeley, 2007.

Evans, Alison, Gang Chen, Eric Ross, Fu-Min Shen, Wen-Yao Lin, and W. Thomas London, "Eight-Year Follow-Up of the 90,000-Person Haimen City Cohort: I. Hepatocellular Carcinoma Mortality, Risk Factors and Gender Differences," Cancer Epidemiology, Biomarkers and Prevention, 2002, 11, 369-376.

Hesser, JE, J Economidou, and BS Blumberg, "Hepatitis B Surface Antigen (Australia Antigen) in Parents and Sex Ratio of Offspring in a Greek population."," Human Biology, December 1975, 47 (4), 415-425.

Lin, Ming-Jen and Ming-Ching Luoh, "Can Hepatitis B Mothers Account for the Number of Missing Women? Evidence from Three Million Newborns in Taiwan," American Economic Review, forthcoming, 2008.

Livadas, D, J Economidou, JE Hesser, DA Koutras, and S Hadziyannis, "Fertility and Sex Ratio of Offspring of Female HBsAg Carriers."," Journal of the Royal Society of Medicine, July 1979, 72, 509-512.

London, W. Thomas, Alison Evans, K McGlynn, K Buetow, P An, L Gao, Eric Lustbader, Eric Ross, Gang Chen, and Fu-Min Shen, "Viral, Host and Enviromental Risk Factors in Hepatocellular Carcinoma: A Prospective Study in Haimen City, China," Interviology, 1995, 38, 155-161.

Oster, Emily, "Hepatitis B and the Case of the Missing Women," Journal of Political Economy, December 2005, 113 (6), 1163-1216. 
Table 1. Summary Statistics on Haimen City Cohort

\begin{tabular}{lcc}
\hline & Entire Sample & Quality Control Sample \\
\hline \hline Sample Size & 67,511 & 2,590 \\
Respondent is Male & $64.7 \%$ & $72.7 \%$ \\
Respondent Age & 58.4 & 70.4 \\
Respondent Hepatitis B Carrier & $15.4 \%$ & $13.0 \%$ \\
Respondent is still Alive & $90.9 \%$ & $100 \%$ \\
Number of Male Children & 1.00 & 2.16 \\
Number of Female Children & 0.95 & 2.31 \\
Share of Children Dead & $1.77 \%$ & $5.70 \%$ \\
Share with Spouse Also Observed & $13.0 \%$ & $10.1 \%$ \\
\hline Notes: This table reports summary statistics for the overall sample, and the quality control \\
sample. Quality control was focused on families with 4 or more children. \\
\hline \hline
\end{tabular}


Table 2. Gender and Parental Hepatitis B: Full Sample

\begin{tabular}{|c|c|c|c|}
\hline \multicolumn{4}{|c|}{ Panel A: No Controls } \\
\hline \multicolumn{4}{|c|}{ Dependent Variable: Child is Male } \\
\hline \multicolumn{4}{|l|}{ Explanatory } \\
\hline \multicolumn{4}{|l|}{ Variables: } \\
\hline \multirow[t]{2}{*}{ Father HBV Carrier } & -.005 & & .0057 \\
\hline & $(.005)$ & & $(.011)$ \\
\hline \multirow[t]{2}{*}{ Mother HBV Carrier } & & -.0015 & -.007 \\
\hline & & $(.006)$ & $(.01)$ \\
\hline \multirow[t]{2}{*}{ constant } & $.516^{* * *}$ & $.516^{* * *}$ & $.507^{* * *}$ \\
\hline & $(.002)$ & $(.002)$ & $(.004)$ \\
\hline Number of Observations & 94,800 & 56,386 & 19,152 \\
\hline \multicolumn{4}{|c|}{ Panel B: With Controls } \\
\hline \multicolumn{4}{|c|}{ Dependent Variable: Child is Male } \\
\hline Father HBV Carrier & $\begin{array}{l}-.004 \\
(.005)\end{array}$ & & $\begin{array}{l}.0072 \\
(.011)\end{array}$ \\
\hline \multicolumn{2}{|l|}{ Mother HBV Carrier } & $\begin{array}{l}-.0019 \\
(.006)\end{array}$ & $\begin{array}{l}-.0053 \\
(.01)\end{array}$ \\
\hline Parent Age & $\begin{array}{l}-.0053^{* * *} \\
(.002)\end{array}$ & $\begin{array}{l}-.0071^{* * *} \\
(.003)\end{array}$ & $\begin{array}{l}-.0054 \\
(.005)\end{array}$ \\
\hline Parent Age Sq. & $\begin{array}{l}.0001^{* * *} \\
(.000)\end{array}$ & $\begin{array}{l}.0001^{* * *} \\
(.000)\end{array}$ & $\begin{array}{l}.0001 \\
(.000)\end{array}$ \\
\hline Birth Order $=2$ & $\begin{array}{l}.0252^{* * *} \\
(.004)\end{array}$ & $\begin{array}{l}.0275^{* * *} \\
(.005)\end{array}$ & $\begin{array}{l}.0298^{* *} \\
(.009)\end{array}$ \\
\hline Birth Order $=3$ & $\begin{array}{l}.0349^{* * *} \\
(.006)\end{array}$ & $\begin{array}{l}.0414^{* * *} \\
(.008)\end{array}$ & $\begin{array}{l}.0257^{* * *} \\
(.012)\end{array}$ \\
\hline Birht Order $=4+$ & $\begin{array}{l}.0742^{* * *} \\
(.007)\end{array}$ & $\begin{array}{l}.093^{\text {*** }} \\
(.01)\end{array}$ & $\begin{array}{l}.1152^{* *} \\
(.015)\end{array}$ \\
\hline Number of Kids & $\begin{array}{l}-.0435^{* * *} \\
(.002)\end{array}$ & $\begin{array}{l}-.0514^{* * *} \\
(.003)\end{array}$ & $\begin{array}{l}-.0569^{* * *} \\
(.004)\end{array}$ \\
\hline constant & $\begin{array}{l}.633^{* * *} \\
(.059)\end{array}$ & $\begin{array}{l}.682^{* * *} \\
(.075)\end{array}$ & $\begin{array}{l}.609^{* * *} \\
(.154)\end{array}$ \\
\hline Township Fixed Effects & YES & YES & YES \\
\hline Number of Observations & 94,800 & 56,386 & 19,152 \\
\hline \multicolumn{4}{|c|}{$\begin{array}{l}\text { Notes: This table reports effects of parental hepatitis B status on child gender in the } \\
\text { Chinese sample. Column } 1 \text { includes all children for whom we observe paternal hepatitis; } \\
\text { Column } 2 \text { includes all children for whom we observe maternal hepatitis. Column } 3 \text { includes } \\
\text { only those children (a smaller sample) for whom both parents are in the cohort, so we see } \\
\text { both of their hepatitis carrier status. }\end{array}$} \\
\hline
\end{tabular}


Table 3. Gender and Parental Hepatitis B: Sub-Samples

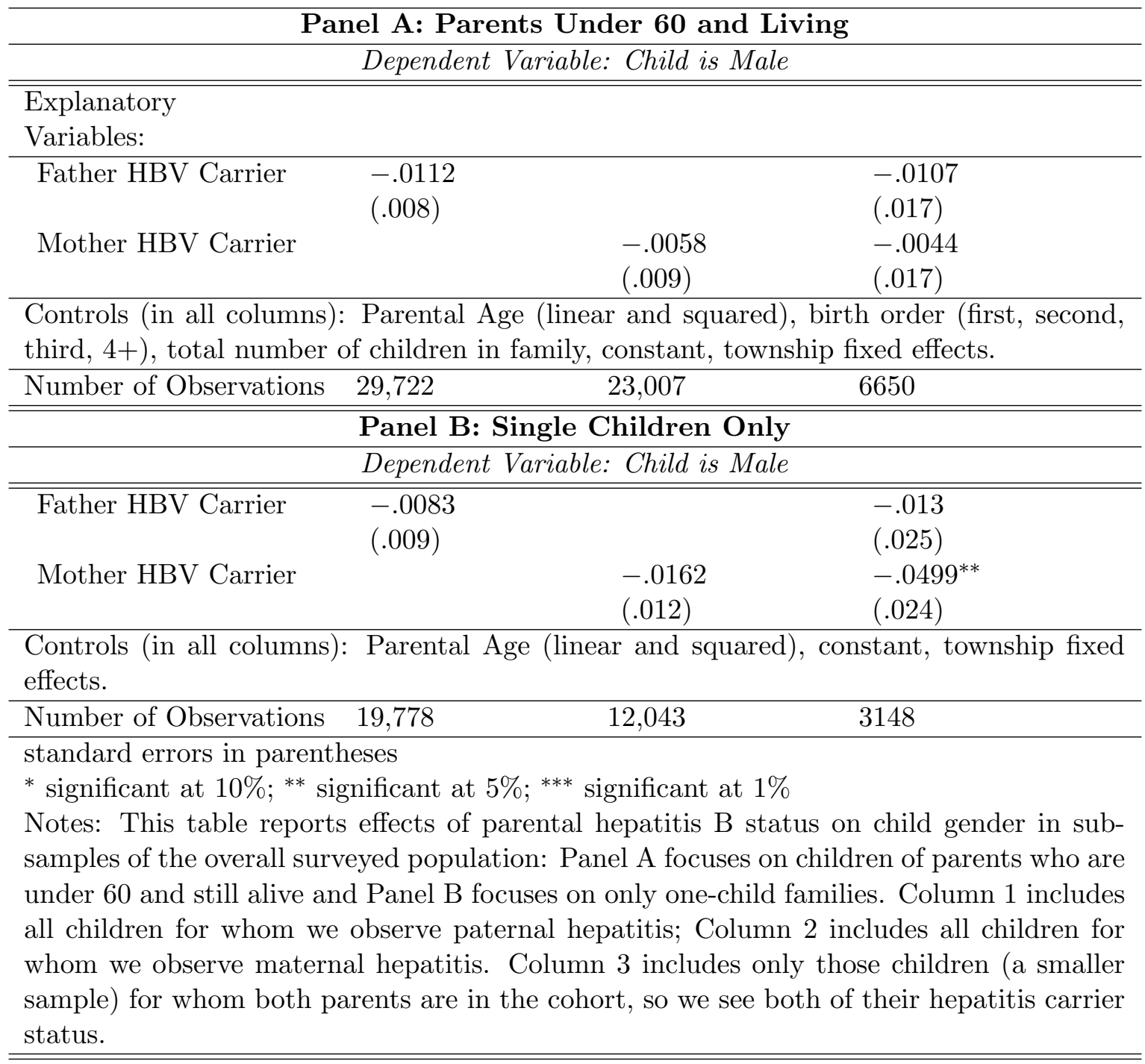


Table 4. Gender and Parental Hepatitis B: Quality Control Data

\begin{tabular}{|c|c|c|}
\hline \multicolumn{3}{|c|}{ Dependent Variable: Child is Male } \\
\hline \multicolumn{3}{|l|}{ Explanatory } \\
\hline \multicolumn{3}{|l|}{ Variables: } \\
\hline \multirow[t]{2}{*}{ Father HBV Carrier } & .0227 & \\
\hline & $(.017)$ & \\
\hline \multirow[t]{2}{*}{ Mother HBV Carrier } & & -.0192 \\
\hline & & $(.025)$ \\
\hline \multirow[t]{2}{*}{ Parental Age } & -.0172 & -.016 \\
\hline & $(.016)$ & $(.022)$ \\
\hline \multirow[t]{2}{*}{ Parental Age Sq. } & .0002 & .0002 \\
\hline & $(0)$ & $(0)$ \\
\hline \multirow[t]{2}{*}{ Birth Order $=2$} & .0077 & .0368 \\
\hline & $(.016)$ & $(.025)$ \\
\hline \multirow[t]{2}{*}{ Birth Order $=3$} & .0206 & $.0603^{* *}$ \\
\hline & $(.016)$ & $(.027)$ \\
\hline \multirow[t]{2}{*}{ Birth Order $=4+$} & $.0267^{*}$ & $.0592^{* *}$ \\
\hline & $(.015)$ & $(.024)$ \\
\hline \multirow[t]{2}{*}{ constant } & $.918^{*}$ & .786 \\
\hline & $(.547)$ & $(.759)$ \\
\hline Number of Observations & 8433 & 3175 \\
\hline $\mathrm{R}^{2}$ & .01 & .02 \\
\hline \multicolumn{3}{|c|}{ standard errors in parentheses } \\
\hline \multicolumn{3}{|c|}{$\begin{array}{l}\text { Notes: This table reports effects of parental hepatitis B status on } \\
\text { child gender in the quality controls sample for which individual in- } \\
\text { terviews were conducted. Column } 1 \text { includes all children for whom } \\
\text { we observe paternal hepatitis; Column } 2 \text { includes all children for } \\
\text { whom we observe maternal hepatitis. }\end{array}$} \\
\hline
\end{tabular}


Figure 1:

Hepatitis B Carrier Status and Share Male Among Offspring

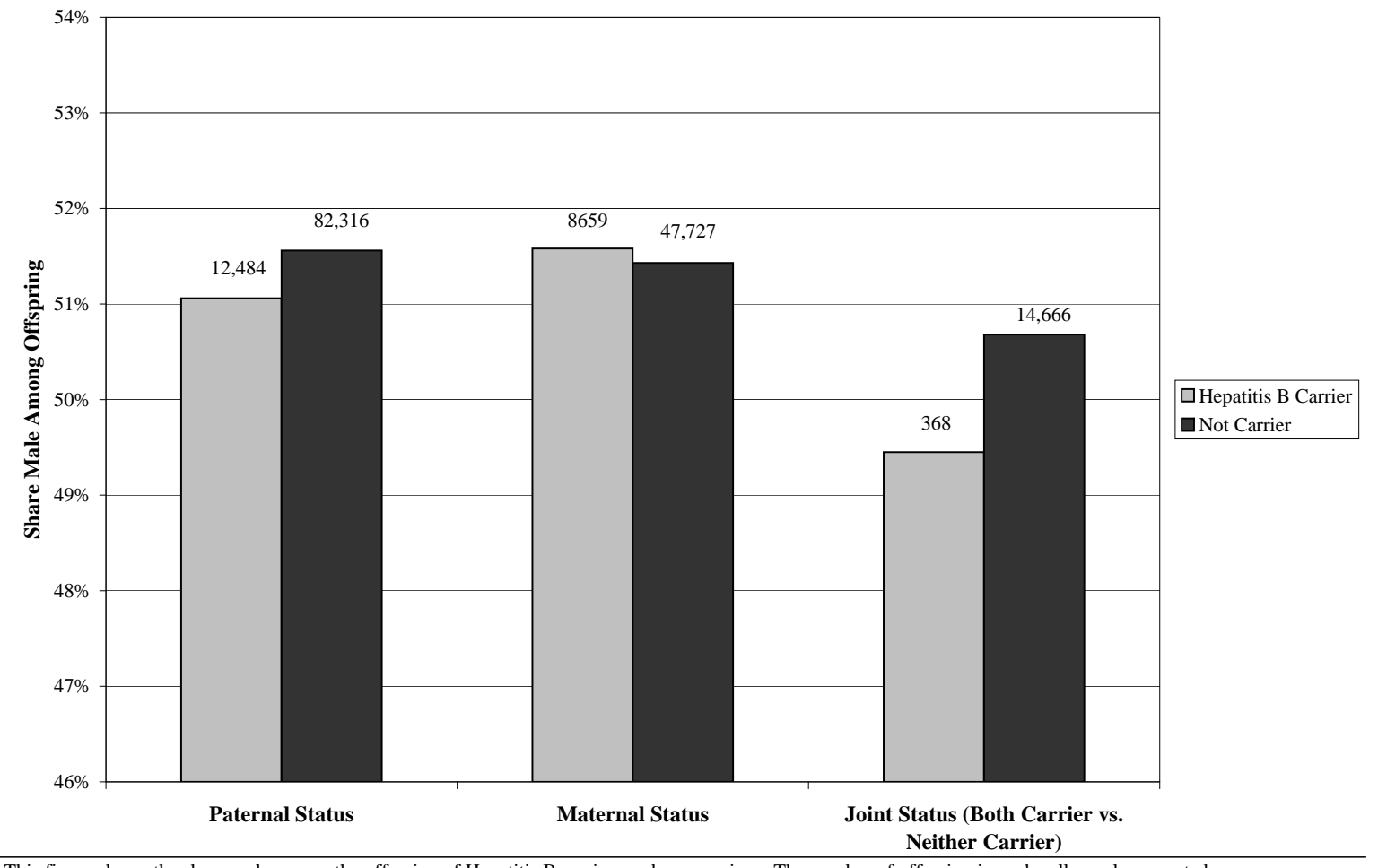

This figure shows the share male among the offspring of Hepatitis B carriers and non-carriers. The number of offspring in each cell are also reported. 